\title{
The Force-Velocity Relationship in Older People: Reliability and Validity of a Systematic Procedure
}

\author{
Authors \\ Julian Alcazar', 2, Carlos Rodriguez-Lopez 1, 2, Ignacio Ara', 2, Ana Alfaro-Acha', 3, Asier Mañas-Bote', 2, \\ Amelia Guadalupe-Grau2, 4, Francisco Jose García-García ${ }^{2,4}$, Luis M. Alegre ${ }^{1,2}$
}

\section{Affiliations}

1 GENUD Toledo Research Group, Universidad de CastillaLa Mancha, Toledo, Spain

2 CIBER of Frailty and Healthy Aging (CIBERFES), Madrid, Spain

3 Hospital Virgen del Valle, Complejo Hospitalario de Toledo, Toledo, Spain

4 ImFINE Research Group, Universidad Politécnica de Madrid, Madrid, Spain

\section{Key word}

aging, muscle power, power training, resistance training, functional ability, muscle function

accepted 26.08.2017

\section{Bibliography}

DOI https://doi.org/10.1055/s-0043-119880

Published online: 2017

Int J Sports Med

(C) Georg Thieme Verlag KG Stuttgart · New York

ISSN 0172-4622

\section{Correspondence}

Dr. Luis M. Alegre, PhD

University of Castilla-La Mancha

Faculty of Spors Sciences, Campus Tecnológico

Avda. Carlos III s/n

45071 Toledo

Spain

Tel.: + 34/925/268 800, e:5520, Fax: + 34/925/268 846

Luis.Alegre@uclm.es

\section{ABSTRACT}

This study compared the reliability and validity of different protocols evaluating the force-velocity (F-V) relationship and muscle power in older adults. Thirty-one older men and women $(75.8 \pm 4.7$ years) underwent two $F-V$ tests by collecting the mean and peak force and velocity data exerted against increasing loads until one repetition maximum (1RM) was achieved in the leg press exercise. Two attempts per load were performed, with a third attempt when F-V points deviated from the linear $\mathrm{F}-\mathrm{V}$ regression equation. Then, the subjects performed $2 \times 3$ repetitions at $60 \% 1 \mathrm{RM}$ to compare purely concentric and eccentric-concentric repetitions. The Short Physical Performance Battery was conducted to assess the validity of the different protocols. Significant differences were found in maximal power (Pmax) between mean and peak values and between protocols differing in the number of attempts per load $(p<0.01)$. Registering mean values, a third attempt, and multiple loads $(>3)$, was significantly more reliable (Pmax: $C V=2.6 \%$; $I C C=0.99)$ than the other alternatives. Mean values were also observed to be more associated with physical function than peak values $\left(R^{2}=0.34\right.$ and 0.15 , respectively; $\left.p<0.05\right)$. No significant differences were observed between concentric and eccentric-concentric repetitions. Thus, collecting mean force and velocity values against multiple loads, while monitoring the linearity of the F-V relationship, seemed to be the more adequate procedure to assess the F-V profile and muscle power in older adults.

\section{Introduction}

Muscle power has increasingly been shown to be an important determinant of athletic performance [36]. However, the importance of muscle power oversteps the context of sport, and early studies observed a strong association between muscle power and several indices of functional performance in older adults [1]. Muscle power has a greater influence on functional mobility in older adults than any other physical capacity [6], and it has been recognized as a priority target of resistance training interventions aimed at enhancing physical function and preserving independence in later life [21].
The individual capacity to produce muscle power depends on the ability to exert force and velocity, and consequently, on the forcevelocity ( $F-V$ ) relationship. The evaluation of the $F-V$ relationship in older adults might help to identify specific neuromuscular deficits and optimize the design of exercise programs to counteract such deficits and improve physical performance, as has been reported in young adults regarding jumping performance [25].

The evaluation of the F-V relationship usually consists of registering the movement velocity exerted against increasing loads (isotonic evaluation) or measuring the force exerted at different constant 
velocities (isokinetic evaluation). The latter might present some disadvantages for the evaluation of physical function in older adults, because isokinetic movement rarely occurs during functional tasks. Thus, the evaluation of the F-V relationship can be a time-consuming and fatiguing task for an older subject, who has to perform a relatively high number of repetitions against different loads/velocities to draw the whole F-V relationship. Fortunately, the $F-V$ relationship during multi-joint movements has been shown to follow a strong linear regression pattern [4, 23], which permits the F-V relationship to be accurately drawn from a few F-V points by means of a linear regression equation [39], something that could facilitate the evaluation of the $\mathrm{F}-\mathrm{V}$ relationship in older adults. However, whereas in young adults a recent study demonstrated that a two-load method was a feasible approach to assess the F-V relationship in an upper-body resistance exercise [31], the validity and reliability of the determination of the $F-V$ relationship through the evaluation of a few loads have not been previously analyzed in older adults. In addition, some concerns remain regarding the protocol conducted for $\mathrm{F}-\mathrm{V}$ and muscle power measurement in older adults (e. g., collecting mean vs. peak values, concentric vs. eccentric-concentric muscle actions, number of attempts performed with each increasing load, and the total number of loads evaluated to build the F-V relationship).

Thus, the main goals of this investigation were to compare the reliability of different protocols that evaluate the F-V relationship, and to assess the validity and reliability of a systematic procedure to assess the $\mathrm{F}-\mathrm{V}$ relationship and muscle power in older adults.

\section{Methods}

\section{Participants}

Subjects were recruited through advertisements and community newsletters. Participants were screened if they were aged $\geq 70$ years, community-dwelling, and reported no participation in a regular resistance training program in the previous 6 months. The subjects completed a medical history questionnaire and performed the Short Physical Performance Battery (SPPB) [17] to assess their physical function. Exclusion criteria included a SPPB score $<4$, severe cognitive impairment (mini-mental state examination (MMSE) score $<20$ ), neuromuscular or joint injury, stroke, myocardial infarction or bone fracture in the previous six months, uncontrolled hypertension (>200/110 $\mathrm{mmHg}$ ) or terminal illness. A total of 31 older subjects ( 17 women) were given medical acceptance by the study physician and met the entry criteria to participate in the study ( $\triangleright$ Table 1). All the subjects gave their informed consent and the study was performed in accordance with the Helsinki Declaration

Table 1 Main characteristics of the subjects.

\begin{tabular}{|l|c|c|}
\hline Variable & Mean (SD) & Range \\
\hline Age (years) & $75.8(4.7)$ & $70.2-84.9$ \\
\hline BMI $\left(\mathrm{kg} / \mathrm{m}^{2}\right)$ & $30.2(4.4)$ & $19.5-43.0$ \\
\hline SPPB score & $10.6(2.1)$ & $4.0-12.0$ \\
\hline MMSE score & $26.2(3.0)$ & $20.0-30.0$ \\
\hline
\end{tabular}

BMI: body mass index. MMSE: mini-mental state examination. SD: standard deviation. SPPB: short physical performance battery and approved by the Ethical Committee of the Toledo Hospital. This study meets the ethical standards in sports and exercises science research [18].

\section{Testing Procedures}

First, the participants attended 2 familiarization sessions. Then, leg muscle power testing was conducted twice, on separate days, by the same evaluator, with identical equipment and procedures, and at the same time of the day with a difference of 7 days in between.

\section{F-V and muscle power testing}

Before each session, subjects performed a general warm-up consisting of 5 min of cycling (Ergoline, 800S, Bitz, Germany) at a selfreported light intensity (10-40 W), plus a specific warm-up in which the subjects performed 3 sets of 10 repetitions on the leg press equipment (BH Fitness, L050, Vitoria, Spain) at an intensity equivalent to $40 \%$ of their body mass with a 1 -min resting period between sets. The last 3 repetitions of each set were performed explosively. During the familiarization sessions, the subjects were instructed on how to sit on the leg press, perform repetitions with a proper technique, and breathe while performing the exercise (expiration during the concentric phase and inspiration during the eccentric phase to avoid the Valsalva maneuver). The familiarization phase also served to identify and record the correct position of each subject on the leg press machine, to reproduce the same range of movement (ROM) across the subjects and testing sessions (from $100^{\circ}$ and $90^{\circ}$ at the hip and knee joints, respectively, to $180^{\circ}$ or full extension).

During the F-V and muscle power testing procedure, the subjects performed 2 sets of 1 repetition with increasing loads (10-kg increments) from $40 \%$ of their body mass. When the subjects failed to lift a certain load, it was decreased by $5 \mathrm{~kg}$ until the one repetition maximum (1RM) was achieved. Force and velocity data during the concentric phase of each repetition were recorded by a linear position transducer device (T-Force System, Ergotech, Murcia, Spain). The duration of the recovery time between sets was designed according to the mean velocity exerted by the subjects in the preceding repetition ( $>0.50 \mathrm{~m} \cdot \mathrm{s}^{-1}: 60 \mathrm{~s}$ of recovery time; $0.30-0.50 \mathrm{~m} \cdot \mathrm{s}^{-1}: 90 \mathrm{~s}$ of recovery time; $<0.30 \mathrm{~m} \cdot \mathrm{s}^{-1}: 120 \mathrm{~s}$ of recovery time). The subjects were continually encouraged to perform each repetition as fast and strongly as possible. To ensure that all the repetitions were performed at maximal speed, force and velocity data from each repetition were computed in a Microsoft Excel ${ }^{\circledR}$ template (supplemental material), and the highest mean velocity for each load was plotted. Because the F-V relationship was expected to follow a linear relationship [23], a linear regression equation was fitted simultaneously during the F-V evaluation. When the highest mean velocity exerted against a certain load deviated more than $0.03 \mathrm{~m} \cdot \mathrm{s}^{-1}$ from the estimated value based on the regression analysis obtained with the preceding repetitions, a third repetition was performed with that specific load. When a participant was not able to exert his/her potentially maximal speed with a certain load, and a deviation greater than $0.03 \mathrm{~m} \cdot \mathrm{s}^{-1}$ remained, that load was discarded and the F-V relationship was computed considering the remaining loads. The cut-off point of $0.03 \mathrm{~m} / \mathrm{s}$ was selected based on other studies implementing a velocity-based strength training program [30] and according to pilot testing conducted in our laboratory. In addition, after the 1 RM determination and 5 min of re- 
covery time, the subjects were asked to perform 2 sets of 3 repetitions at $60 \% 1 \mathrm{RM}$ in order to compare a single-repetition per set (SR; a purely concentric muscle action) vs. a multiple-repetition per set (MR; containing eccentric-concentric muscle actions) protocol. The highest mean velocity produced from the first repetition of each set (only concentric) was compared against the highest mean velocity produced from the second and third repetitions of each set (eccentric-concentric).

\section{Adverse events}

Adverse events were carefully monitored for 3 weeks in which data collection was conducted for each subject. An adverse event was defined as any unfavorable or unintended event (pain, discomfort, injury or accident) that occurred during the course of the study and that might not necessarily be caused by the study procedures. In case of an adverse event, it would be additionally classified as studyrelated or non-study-related based on its origin and etiology.

\section{Data analysis}

Mean force and velocity values from each repetition, and force and velocity values exerted at peak power within each repetition were acquired from all the evaluations to compare both sets of data. Hereafter, mean data were used for the comparison between procedures.

As a reference method, the $F-V$ relationship was calculated from mean force and velocity data recorded from all the measured loads (multiple-load (M-L) protocol), with 2 attempts per load, and an additional attempt as mentioned in a previous section $\left(2+1^{\text {-at- }}\right.$ tempt protocol).

For comparison, we also calculated the F-V relationship not considering the third attempt (2-attempt protocol) if it was performed. In addition, a short version of the entire protocol considering 3 loads (3-L) was also studied by selecting the first, the middle and the last load performed by the subjects.

In all cases, several variables were extracted from the F-V regression equation. Force at zero velocity (i. e., theoretical maximal isometric force) was obtained from the force-intercept $\left(F_{0}\right)$, while velocity at zero force (i.e., maximal velocity with no load) was calculated as the velocity-intercept $\left(\mathrm{V}_{0}\right)$. The slope of the $\mathrm{F}-\mathrm{V}$ relationship $\left(\mathrm{S}_{\mathrm{FV}}\right)$ was obtained from the following equation (equation 1 ):

$$
\mathrm{S}_{\mathrm{FV}}=-\frac{\mathrm{F}_{0}}{\mathrm{~V}_{0}}
$$

The linear relationship between force and velocity allowed for maximal muscle power $\left(\mathrm{P}_{\max }\right)$ calculation using the following formula (equation 2):

$$
\mathrm{P}_{\max }=\frac{\mathrm{F}_{0} \times \mathrm{V}_{0}}{4}
$$

The optimal load $\left(\mathrm{L}_{\text {opt }}\right)$ at which the subjects exerted their $\mathrm{P}_{\max }$ was also calculated.

\section{Statistical analysis}

Sample size calculation was conducted based on the intra-class correlation coefficient (ICC) using the $R$ package ( $R$ version 3.2.4 revised) [10]. The arguments introduced were the preliminary ICC of Pmax values (model 2,1 ) obtained in a group of 10 older subjects
(ICC $=0.977)$, the null hypothesis (ICC $=0.90)$, the number of ratings of each subject (2), the number of tails (2) and the desired statistical power (0.80). A minimum of 15 older subjects was required to satisfy the arguments introduced into the R package.

All data were examined statistically for normality of distribution with the Shapiro-Wilk's test, and standard descriptive statistics were used for continuous variables.

Significant differences between protocols (collecting mean values vs. peak values; a 2 -attempt vs. a $2+1$-attempt protocol; an $\mathrm{M}-\mathrm{L}$ vs. a 3-L protocol; and an SR vs. an MR protocol) were assessed with Student's t-tests for independent samples.

Reliability of the F-V relationship and muscle power values obtained from the different procedures were evaluated using different approaches [20]. Within-subject variation was assessed by means of the standard error of measurement (SEM), also reported in relative terms (SEM \%), and by the coefficient of variation (CV); changes in the mean of the different protocols between sessions were analyzed with Student's t-tests for dependent samples; and retest correlation was evaluated using the ICC (model 2,1).

In addition, the different procedures were also compared regarding their associations with the SPPB score, as a measure of construct validity. For this analysis, $P_{\max }$ values were extracted from the second evaluation, because of the greater experience gained by the subjects after the first evaluation. Bivariate linear and quadratic regression analyses were performed because the relationship between muscle power and physical function has been reported to follow a quadratic relationship in some cases [2]. The coefficient of determination $\left(R^{2}\right)$ change was used to compare the linear and quadratic models. Statistical analyses were performed with SPSS v20 (SPSS Inc., Chicago, Illinois, USA), and the level of significance was set at $\alpha=0.05$.

\section{Results}

\section{Testing procedure and adverse events}

Force and velocity data showed a significant linear relationship in all subjects, with individual $R^{2}$ values ranging from 0.95 to 1.00 , whereas quadratic models did not significantly improve the $R^{2}$ values $(p>0.05)$. The $F-V$ relationship was evaluated by measuring force and velocity data from $6.2 \pm 1.8$ loads and $13.2 \pm 3.7$ repetitions per subject. On average, $0.8 \pm 0.8$ loads were discarded because they deviated from the $\mathrm{F}-\mathrm{V}$ regression equation $\left(>0.03 \mathrm{~m} \cdot \mathrm{s}^{-1}\right)$. Finally, $5.1 \pm 1.9$ loads were considered to obtain the $\mathrm{F}-\mathrm{V}$ relationship of the participants. The evaluation of the F-V relationship was carried out in $26.9 \pm 8.0$ min per subject. No adverse events were registered throughout the study.

\section{Reliability of mean vs. peak values}

There were no significant differences for any protocol between testing sessions ( $\triangleright$ Table 2). However, $P_{\max }$ derived from peak values was significantly higher than that observed from mean values. Absolute reliability was higher when mean values were considered in comparison with peak values ( $\triangleright$ Table 3 ). SEM \% values of $V_{0}$ and $\mathrm{P}_{\max }$ were significantly lower and the ICC for $\mathrm{P}_{\max }$ significantly higher when collecting mean compared with peak values. 
- Table 2 Comparison between different protocols and testing sessions to assess the force-velocity relationship and muscle power.

\begin{tabular}{|c|c|c|c|c|}
\hline \multirow{2}{*}{ Variable } & \multirow{2}{*}{ Procedure } & Session 1 & Session 2 & Session 1 vs. 2 \\
\hline & & Mean (SD) & Mean (SD) & $p$ value \\
\hline \multirow[t]{9}{*}{$P_{\max }(W)$} & \multicolumn{4}{|l|}{ Data collection } \\
\hline & Mean values & $242.7(93.0)^{*}$ & $246.5(89.8)^{*}$ & 0.123 \\
\hline & Peak values & 505.5 (207.9) & $530.2(210.7)$ & 0.064 \\
\hline & \multicolumn{4}{|l|}{ Attempts per load } \\
\hline & $2+1$-attempt & $242.7(93.0)^{*}$ & $246.5(89.8)$ & 0.123 \\
\hline & 2-attempt & $235.3(92.4)$ & $244.7(91.7)$ & $0.024^{*}$ \\
\hline & \multicolumn{4}{|l|}{ Number of loads } \\
\hline & $M-L$ & $242.7(93.0)$ & $246.5(89.8)$ & 0.123 \\
\hline & $3-\mathrm{L}$ & $248.7(97.7)$ & $244.0(87.6)$ & 0.325 \\
\hline \multirow[t]{3}{*}{$P_{60 \% 1 R M}(W)$} & \multicolumn{4}{|l|}{ Repetitions per set } \\
\hline & SR & $223.6(84.6)$ & $227.9(88.1)$ & 0.562 \\
\hline & MR & $253.9(90.5)$ & $252.8(93.1)$ & 0.863 \\
\hline
\end{tabular}

MR: multiple-repetition per set protocol. M-L: multiple-load protocol. $P_{\text {max }}$ : maximal muscle power. $P_{60 \% 1 R M}$ : muscle power at $60 \% 1$ RM. SD: standard deviation. SR: single-repetition per set protocol. 2 -attempt: 2 attempts per load. $2_{+1}$-attempt: 2 attempts per load plus an additional load when indicated. 3-L: 3-load protocol. * Significant differences between protocols $(p<0.01) .{ }^{*}$ Significant differences between testing sessions $(p<0.05)$

- Table 3 Reliability comparison of force-velocity parameters obtained from mean and peak values.

\begin{tabular}{|c|c|c|c|c|c|}
\hline Variable & $F_{0}(N)$ & $\mathrm{V}_{0}(\mathrm{~m} / \mathrm{s})$ & $\mathrm{S}_{\mathrm{FV}}$ & $P_{\max }(W)$ & $\mathrm{L}_{\text {opt }}(\mathrm{kg})$ \\
\hline \multicolumn{6}{|l|}{ SEM $[95 \% \mathrm{Cl}]$} \\
\hline Mean values & 99.4 [88.6-114.3] & $0.05[0.05-0.05]$ & $268.5[231.7-319.2]$ & $8.0[7.0-9.6]$ & $5.1[4.5-5.8]$ \\
\hline Peak values & $123.7[110.3-140.7]$ & $0.26[0.23-0.29]$ & $176.1[151.2-210.8]$ & $44.2[37.8-53.1]$ & $6.3[5.6-7.2]$ \\
\hline \multicolumn{6}{|c|}{ SEM [95\% CI] (\%) } \\
\hline Mean values & $9.2[8.1-10.5]$ & $5.7^{*}[5.2-6.3]$ & $21.1[18.2-25.1]$ & $3.3^{*}[2.8-3.9]$ & $9.2[8.1-10.5]$ \\
\hline Peak values & $11.3[10.1-12.8]$ & $13.5[12.2-15.3]$ & $28.3[24.3-33.8]$ & $8.5[10.1-12.8]$ & $11.3[10.1-12.8]$ \\
\hline \multicolumn{6}{|l|}{ CV [95\% Cl] (\%) } \\
\hline Mean values & $5.6[2.5-8.7]$ & $4.8[2.2-7.5]$ & $10.1[4.6-15.7]$ & $2.6[1.5-3.7]$ & $5.5[2.5-8.7]$ \\
\hline Peak values & $7.6[3.7-11.5]$ & $10.6[6.8-14.4]$ & $17.7[10.8-24.5]$ & $5.8[3.5-8.2]$ & $7.6[3.7-11.5]$ \\
\hline \multicolumn{6}{|l|}{ ICC [95\% Cl] } \\
\hline Mean values & $0.91[0.81-0.96]$ & $0.94[0.86-0.97]$ & $0.73[0.47-0.87]$ & $0.99 *[0.98-1.00]$ & $0.91[0.81-0.96]$ \\
\hline Peak values & $0.86[0.70-0.94]$ & $0.77[0.54-0.90]$ & $0.59[0.25-0.80]$ & $0.96[0.90-0.98]$ & $0.86[0.70-0.94]$ \\
\hline
\end{tabular}

$\mathrm{Cl}$ : confidence interval. CV: coefficient of variation. $\mathrm{F}_{0}$ : force-intercept. ICC: intra-class correlation coefficient. $\mathrm{L}_{\text {opt }}$ : optimal load. $\mathrm{P}_{\max }$ : maximal power. SEM: standard error of measurement. $\mathrm{S}_{\mathrm{FV}}$ : slope of the force-velocity relationship. $\mathrm{V}_{0}$ : velocity-intercept. ${ }^{*}$ Significant differences between mean and peak values $(p<0.05)$

\section{Reliability of an SR vs. an MR protocol}

There were no significant differences in mean muscle power exerted at $60 \% 1 \mathrm{RM}$ between testing sessions or between different protocols ( $\triangleright$ Table 2). There were no significant differences in SEM \%, CV or ICC values between protocols ( $\triangleright$ Table 4 ).

\section{Reliability of protocols differing in the number of attempts per load}

The $2+1$-attempt protocol showed no significant differences between testing sessions ( $\triangleright$ Table 2 ). In contrast, $\mathrm{P}_{\max }$ measured by the 2-attempt protocol was found to be significantly different in the second evaluation with respect to the first evaluation. Both protocols were significantly different in the first evaluation. Reliability was significantly higher for the $2_{+}$- than for the 2 -attempt protocol regarding SEM \% values for $\mathrm{V}_{0}$ and $\mathrm{P}_{\max }$, and ICC of $\mathrm{V}_{0}$ values ( $\triangleright$ Table 5).
- Table 4 Reliability comparison of mean muscle power exerted at $60 \%$ 1 RM between the single- and the multiple-repetition per set protocols.

\begin{tabular}{|l|c|c|}
\hline Variable & SR & MR \\
\hline SEM $[95 \% \mathrm{CI}](\mathrm{W})$ & $23.9[20.5-28.6]$ & $20.7[17.8-24.5]$ \\
\hline SEM $[95 \% \mathrm{CI}](\%)$ & $10.6[9.1-12.7]$ & $8.2[7.0-9.7]$ \\
\hline $\mathrm{CV}[95 \% \mathrm{CI}](\%)$ & $8.2[5.3-11.2]$ & $6.5[4.4-8.5]$ \\
\hline $\mathrm{ICC}[95 \% \mathrm{Cl}]$ & $0.93[0.83-0.97]$ & $0.95[0.89-0.98]$ \\
\hline \multicolumn{3}{|l|}{ Cl: confidence interval. CV: coefficient of variation. ICC: intra-class } \\
correlation coefficient. MR: multiple-repetition per set protocol. SEM: \\
standard error of measurement. SR: single-repetition per set \\
protocol. * Significant differences between the SR and MR protocols \\
$(p<0.05)$
\end{tabular}


- Table 5 Reliability comparison of force-velocity parameters obtained from protocols differing in the number of attempts per load and/or number of loads.

\begin{tabular}{|c|c|c|c|c|c|}
\hline Variable & $F_{0}(N)$ & $v_{0}(m / s)$ & $\mathrm{S}_{\mathrm{FV}}$ & $P_{\max }(W)$ & $\mathrm{L}_{\mathrm{opt}}(\mathrm{kg})$ \\
\hline \multicolumn{6}{|l|}{ SEM [95\% Cl] } \\
\hline M-L $\left[2+{ }_{+1}\right.$-attempt $]$ & 99.4 [88.6-114.3] & $0.05[0.05-0.05]$ & $268.5[231.7-319.2]$ & $8.0[7.0-9.6]$ & $5.1[4.5-5.8]$ \\
\hline M-L [2-attempt] & $98.3[90.1-108.1]$ & $0.08[0.07-0.08]$ & 271.5 [241.9-309.3] & $13.4[12.1-15.1]$ & $5.0[4.6-5.5]$ \\
\hline 3-L [2 $+{ }_{+1}$-attempt $]$ & $142.0[129.8-156.5]$ & $0.09[0.09-0.10]$ & $278.1[247.5-317.1]$ & $16.3[14.7-18.3]$ & $7.2[6.6-8.0]$ \\
\hline \multicolumn{6}{|l|}{ SEM [95\% Cl] (\%) } \\
\hline M-L $\left[2_{+1}\right.$-attempt $]$ & $9.2[8.1-10.5]$ & $5.7[5.2-6.3]$ & $21.1[18.2-25.1]$ & 3.3 [2.8-3.9] & 9.2 [8.1-10.5] \\
\hline M-L [2-attempt] & $9.1[8.4-10.0]$ & $8.5^{*}[8.0-9.1]$ & $21.3[19.0-24.3]$ & $5.6 *[5.0-6.3]$ & $9.1[8.4-10.0]$ \\
\hline 3-L [2 ${ }_{+1}$-attempt $]$ & $12.9^{*}[11.8-14.3]$ & $10.2 *$ [9.6-10.9] & $21.6[19.3-24.7]$ & $6.6^{*}[6.0-7.4]$ & $12.9 *[11.8-14.3]$ \\
\hline \multicolumn{6}{|l|}{ CV [95\% Cl] (\%) } \\
\hline M-L $\left[2+{ }_{+1}\right.$-attempt $]$ & $5.6[2.5-8.7]$ & $4.8[2.2-7.5]$ & $10.1[4.6-15.7]$ & $2.6[1.5-3.7]$ & $5.5[2.5-8.7]$ \\
\hline M-L [2-attempt] & $6.3[3.3-9.3]$ & $6.1[2.8-9.4]$ & $12.0[6.5-17.5]$ & $4.4[2.0-6.9]$ & 6.3 [3.3-9.3] \\
\hline 3-L [2 ${ }_{+1}$-attempt $]$ & $9.9[6.6-13.1]$ & $8.5[5.8-11.2]$ & $17.8[12.2-23.5]$ & $4.3[2.7-5.8]$ & 9.9 [6.6-13.1] \\
\hline \multicolumn{6}{|l|}{ ICC [95\% CI] } \\
\hline M-L $\left[2+{ }_{+1}\right.$-attempt $]$ & $0.91[0.81-0.96]$ & $0.94[0.86-0.97]$ & $0.73[0.47-0.87]$ & $0.99[0.98-1.00]$ & $0.91[0.81-0.96]$ \\
\hline M-L [2-attempt] & $0.92[0.82-0.96]$ & $0.85 *[0.68-0.81]$ & $0.75[0.51-0.88]$ & $0.98[0.93-0.99]$ & $0.92[0.82-0.96]$ \\
\hline 3-L [2+1-attempt] & $0.84[0.67-0.93]$ & $0.81[0.60-0.91]$ & $0.75[0.50-0.88]$ & $0.97[0.93-0.99]$ & $0.84[0.67-0.93]$ \\
\hline \multicolumn{6}{|c|}{$\begin{array}{l}\mathrm{Cl} \text { : confidence interval. CV: coefficient of variation. } \mathrm{F}_{0} \text { : force-intercept. ICC: intra-class correlation coefficient. } \mathrm{L}_{\text {opt }}: \text { optimal load. M-L: multiple-load } \\
\text { protocol. } \mathrm{P}_{\max } \text { : maximal power. SEM: standard error of measurement. } \mathrm{S}_{\mathrm{FV}} \text { : slope of the force-velocity relationship. } \mathrm{V}_{0}: \text { velocity-intercept. } 2 \text {-attempt: } 2 \\
\text { attempts per load. } 2_{+1} \text {-attempt: } 2 \text { attempts per load plus an additional load when indicated. } 3 \text {-L: } 3 \text {-load protocol. }{ }^{*} \text { Significantly different compared } \\
\text { with the M-L }\left[2_{+1} \text {-attempt] protocol }(p<0.05)\right.\end{array}$} \\
\hline
\end{tabular}

\section{Reliability of protocols differing in the number of loads}

There were no significant differences in $\mathrm{P}_{\max }$ between testing sessions or protocols regarding the number of loads considered ( $\triangleright$ Table 2). However, the M-L protocol was significantly more reliable than the 3-L protocol, considering their SEM \% values for $\mathrm{F}_{0}$, $\mathrm{V}_{0}, \mathrm{P}_{\max }$ and $\mathrm{L}_{\mathrm{opt}}(\triangleright$ Table 5).

\section{Validity of the different protocols regarding physical function}

Collecting mean values was found to be superior (curvilinear relationship; $R^{2}=0.34$ ) than peak values (linear relationship; $R^{2}=0.15$ ) to predict the participants' SPPB scores. Both the SR and MR protocols showed a significant and similar linear relationship with physical function ( $R^{2}=0.19$ and 0.18 , respectively). $R^{2}$ values were also similar between the $2+{ }$ - and 2 -attempt protocols (both curvilinear relationships; $R^{2}=0.34$ and 0.33 , respectively), and between the $\mathrm{M}-\mathrm{L}$ and $3-\mathrm{L}$ protocols (both curvilinear relationships; both $\left.R^{2}=0.34\right)$.

\section{Discussion}

Our findings showed that a protocol collecting mean force and velocity values from either concentric or eccentric-concentric muscle actions performed against multiple progressive loads was an optimal strategy to evaluate the F-V relationship and muscle power in older adults in terms of reliability and external validity, explaining up to $34 \%$ of the variability in physical function.

The great heterogeneity reported in the literature investigating muscle power in older adults is likely to be partially explained by the different methods and protocols used $[7,37]$. $P_{\max }$ values sig- nificantly differed when collecting mean or peak values. In young adults, there are inconclusive results regarding reliability of muscle power testing, with some evidence in favor of using mean values $[12,14]$, and other evidence supporting the use of peak values [13]. In older adults, one previous study compared the utility of both approaches, and mean values were more strongly associated with the older subjects' muscle quality and size [38]. In this line, we found that mean values were significantly more reliable and better associated with physical function in comparison with peak values, thus mean values might be preferred when evaluating older individuals.

In addition, muscle power can be measured using purely concentric muscle contractions (SR protocol) or stretch-shortening cycle (SSC) actions where eccentric and concentric contractions are performed (MR protocol). Though the SSC is believed to increase neuromuscular performance in young adults [26], contradictory results exist regarding older adults [5, 22]. In our study, the SSC did not improve power values at 60\% 1RM over only-concentric repetitions, and reliability was similar between both protocols. In young adults, an SSC protocol was found to have a greater error than a solely-concentric protocol, although both of them were highly reliable [29]. In the absence of significant differences between the two protocols, we prefer to use the SR protocol due to its simplicity, and overall because it might be a safer alternative for older adults compared with MR protocols, which impose a higher mechanical and cardiovascular load [27], leading to an increased risk of injury or cardiovascular event. However, future studies should evaluate the influence of the SSC on muscle power of older adults over the whole $\mathrm{F}-\mathrm{V}$ relationship.

The main novelty that this study introduces is the implementation of a systematic procedure by which force and velocity data can 
be monitored simultaneously during the F-V assessment, and considering our proposed criteria (deviation $>0.03 \mathrm{~m} / \mathrm{s}$ from the linear regression equation), it can be objectively decided when an additional attempt with a certain load should be performed, and when a load should be discarded from the F-V analysis. Several studies in young adults have reported lower reliability values for $\mathrm{V}_{0}, \mathrm{P}_{\max }$, or $S_{F V}$ compared with other $F-V$ measures $[13,15]$. Our procedure partially solved this problem, because it was found to significantly improve the reliability of $P_{\max }$ and $V_{0}$ values (SEM \% $=3.3$ and $5.7 \%$, respectively) over a traditional protocol with a fixed number of attempts (SEM \% $=5.6$ and $8.5 \%$, respectively). No studies have previously evaluated the reliability of the $\mathrm{F}-\mathrm{V}$ relationship in older adults. However, we found similar, or in some cases greater, reliability values in our non-experienced older adults compared with those reported in physically active young adults and athletes during leg exercise performance ( $>$ Table 6 ) $[8,11,24,28,33]$. In comparison with other measures evaluated in older adults, our $F_{0}$ values were more reliable $(C V=5.6 \%)$ than those obtained from $1 \mathrm{RM}$ values ( $C V=6.3-6.7 \%)$ [32], and the same occurred with our $P_{\max }$ values $(I C C=0.99)$ compared with muscle power extracted by isokinetic dynamometry $(I C C=0.94)$ [19]. The number of attempts per load has been found to be an important issue when measuring muscle power in older adults [7], and an adequate number of attempts can be objectively reached by means of the procedure presented in this work.

On the other hand, we observed in the literature that most of studies evaluating muscle power in older adults conducted a 1RM test prior to muscle power testing, in the same session $[3,7,9,22,34]$ or on a separate day [3]. Thus, the time expended for testing, plus the corresponding resting period between tests (up to $30 \mathrm{~min}$ in some studies) $[9,34]$, increased substantially the duration of the evaluation. Our subjects started the test with a relative load based on their body weight, so a $1 \mathrm{RM}$ test prior to the F-V evaluation was not necessary, reducing the total time required for $\mathrm{F}-\mathrm{V}$ testing to $\sim 27 \mathrm{~min}$. In addition, the $1 \mathrm{RM}$ evaluation might not be necessary, because the $F-V$ regression equation can be plotted without those force and velocity values, which may be an attractive approach to apply in those more vulnerable subjects with a higher risk of injury [35]. A short version of the entire procedure was also studied, consisting of evaluating the F-V relationship against 3 loads, which could reduce to $\sim 13$ min the time needed to conduct the F-V test. This 3-L protocol showed no significant differences in $\mathrm{P}_{\max }$ values in comparison with the entire protocol, though CV values were significantly higher for the short version. In any case, the 3-L protocol showed good reliability for $\mathrm{F}_{0}, \mathrm{~V}_{0}$ and $\mathrm{L}_{\mathrm{opt}}$ $(C V<10 \%$; ICC $>80)$, and excellent reliability for $P_{\max }(C V=4.3 \%$; ICC $=0.97$ ), while maintaining the same ability to predict SPPB values as the extended protocol. Other authors have proposed and validated the application of a short protocol in young adults by which the F-V relationship can be deduced through the evaluation of only 2 loads $[31,39]$. Though it might be an advantageous approach for experienced young adults, we recommend avoiding the use of a 2-load protocol in older adults. The implementation of an $\mathrm{F}-\mathrm{V}$ test demands the subject to exert maximal force and velocity against each load. By means of a 2-load protocol it is not possible to test whether the subjects are performing the exercise repetitions as fast and strongly as possible, because $R^{2}$ values will always be equal to 1 and deviations of the $\mathrm{F}-\mathrm{V}$ points from the linear regression equation equal to 0 , independently of the subjects' ability to exert their maximal force and velocity. In contrast, the assessment of an additional load (3-L protocol) can help the evaluator to determine whether the $\mathrm{F}-\mathrm{V}$ values are sufficiently fitted to the lin-

- Table 6 Comparison of the reliability values found in the present investigation (bold data) with those reported in the literature.

\begin{tabular}{|c|c|c|c|c|c|c|}
\hline Study & Sample & Exercise & $F_{0}(N)$ & $v_{0}(m / s)$ & $\mathrm{S}_{\mathrm{Fv}}$ & $P_{\max }(W)$ \\
\hline \multicolumn{7}{|l|}{$\mathrm{CV}[95 \% \mathrm{Cl}](\%)$} \\
\hline Systematic protocol (>3 loads) & Older adults & LP & $5.6[2.5-8.7]$ & $4.8[2.2-7.5]$ & $10.1[4.6-15.7]$ & $2.6[1.5-3.7]$ \\
\hline Systematic protocol (3 loads) & Older adults & LP & $9.9[6.6-13.1]$ & $8.5[5.8-11.2]$ & $17.8[12.2-23.5]$ & $4.3[2.7-5.8]$ \\
\hline Rahmani et al. (33) & Young athletes & SQ & - & - & 25.8 & $6.2-7.5$ \\
\hline \multirow[t]{2}{*}{ Cuk et al. (8) } & Young adults & SJ & 5.1 & 6.0 & 9.8 & 5.4 \\
\hline & & CM] & 2.7 & 3.3 & 5.7 & 2.4 \\
\hline \multirow[t]{2}{*}{ García-Ramos et al. (11) } & Young adults & SJ & $4.2-6.7$ & $5.1-7.5$ & $7.2-14.0$ & $3.4-4.2$ \\
\hline & & CMJ & $2.7-3.9$ & $4.9-6.5$ & $8.2-10.1$ & $2.4-4.5$ \\
\hline Meylan et al. (28) & Youth people & SQ & $7.2-8.0$ & $11.2-16.4$ & $23.6-24.8$ & $6.1-12.2$ \\
\hline \multicolumn{7}{|l|}{ ICC [95\% Cl] } \\
\hline Systematic protocol ( >3 loads) & Older adults & LP & $0.91[0.81-0.96]$ & $0.94[0.86-0.97]$ & $0.73[0.47-0.87]$ & $0.99[0.98-1.00]$ \\
\hline Systematic protocol (3 loads) & Older adults & LP & $0.84[0.67-0.93]$ & $0.81[0.60-0.91]$ & $0.75[0.50-0.88]$ & $0.97[0.93-0.99]$ \\
\hline Rahmani et al. (33) & Young athletes & SQ & - & - & - & $0.69-0.88$ \\
\hline Jennings et al. (5) & Young adults & SJ & - & - & - & $0.97[0.95-0.98]$ \\
\hline \multirow[t]{2}{*}{ Cuk et al. (8) } & Young adults & SJ & $0.95[0.85-0.98]$ & $0.93[0.80-0.97]$ & $0.96[0.87-0.98]$ & $0.93[0.81-0.97]$ \\
\hline & & CMJ & $0.98[0.95-0.99]$ & $0.96[0.89-0.98]$ & $0.94[0.94-0.99]$ & 0.98 [0.96-0.99] \\
\hline \multirow[t]{2}{*}{ García-Ramos et al. (11) } & Young adults & SJ & $0.75-0.88$ & $0.77-0.84$ & $0.77-0.82$ & $0.91-0.94$ \\
\hline & & CMJ & $0.88-0.95$ & $0.79-0.89$ & $0.69-0.88$ & $0.90-0.97$ \\
\hline Meylan et al. (28) & Youth people & SQ & $0.71-0.78$ & $0.57-0.80$ & $0.35-0.54$ & $0.91-0.97$ \\
\hline
\end{tabular}

Cl: confidence interval. CV: coefficient of variation. ICC: intraclass correlation coefficient. LP: leg press. SQ: squat. SJ: squat jump. CMJ: countermovement jump. $\mathrm{F}_{0}$ : force-intercept. $\mathrm{V}_{0}$ : velocity-intercept. $\mathrm{S}_{\mathrm{Fv}}$ : slope of the force-velocity relationship. $\mathrm{P}_{\text {max }}$ : maximal power 
ear regression equation, or conversely, whether the subject has not exerted her/his maximal effort with a certain load. In the last case, it can be decided to perform an additional attempt with that specific load, or eliminate that load from the analysis and attempt a new load. In this sense, it is important that loads are sufficiently distributed along the F-V relationship to reduce the possible error of estimations.

Another practical issue included in our testing protocol was that we used contraction velocity to individualize rest intervals between repetitions. This objective measure has been found to be an excellent indicator of exercise intensity and muscle fatigue [16].

Importantly, no adverse events were registered during the study period despite approximately $1,667 \mathrm{~min} \cdot$ subject / 818 repetitions - subject of exposure time/volume being registered. Our subjects ranged from older adults with adequate physical performance $(\mathrm{SPPB}=12 ; n=6)$ to older adults with severe impairments in functional mobility (SPPB $=4-6 ; n=4)$. Therefore, this systematic procedure seems to be adequate for a wide range of older adults independent of their functional states.

In conclusion, we present a valid, reliable, safe and systematic procedure to assess the $\mathrm{F}-\mathrm{V}$ relationship and muscle power in older adults. Registering mean force and velocity data from repetitions performed against multiple increasing loads seemed to be an optimal protocol. Importantly, a procedure by which researchers and practitioners can objectively decide when an additional attempt with a certain load should be performed or when a certain load should be discarded from the F-V analysis was proposed, improving reliability and validity of $\mathrm{P}_{\max }$ values in older adults. With this procedure, muscle power explained a third of the variability in physical function of the older adults. Finally, a short version of this procedure was also validated and might be an excellent choice for clinical and practical settings due to its low time requirement and adequacy for older adults at different functional trajectories.

\section{Acknowledgements}

This work was supported by the Ministerio de Economía y Competitividad of the Government of Spain (grant number DEP201569386-R) (MINECO/FEDER, EU), by the Biomedical Research Networking Center on Frailty and Healthy Aging (CIBERFES) and FEDER funds from the European Union (CB16/10/00477 and CB16/10/00456), and by the Ministerio de Educación, Cultura y Deporte of the Government of Spain (grant number FPU014/05106 to J. A.).

\section{Conflict of Interest}

The authors have no conflict of interest to declare.

\section{References}

[1] Bassey EJ, Fiatarone MA, O'Neill EF, Kelly M, Evans W], Lipsitz LA. Leg extensor power and functional performance in very old men and women. Clin Sci 1992; 82: 321-327
[2] Bean JF, Kiely DK, Herman S, Leveille SG, Mizer K, Frontera WR, Fielding RA. The relationship between leg power and physical performance in mobility-limited older people. J Am Geriatr Soc 2002; 50: 461-467

[3] Beltran Valls MR, Dimauro I, Brunelli A, Tranchita E, Ciminelli E, Caserotti P, Duranti G, Sabatini S, Parisi P, Parisi A, Caporossi D. Explosive type of moderate-resistance training induces functional, cardiovascular, and molecular adaptations in the elderly. Age 2014; 36 : 759-772

[4] Bosco C, Belli A, Astrua M, Tihanyi ], Pozzo R, Kellis S, Tsarpela O, Foti C, Manno R, Tranquilli C. A dynamometer for evaluation of dynamic muscle work. Eur J Appl Physiol 1995; 70: 379-386

[5] Bosco C, Komi PV. Influence of aging on the mechanical behavior of leg extensor muscles. Eur J Appl Physiol 1980; 45: 209-219

[6] Byrne C, Faure C, Keene DJ, Lamb SE. Ageing, muscle power and physical function: a systematic review and implications for pragmatic training interventions. Sports Med 2016, doi:10.1007/s40279-0160489-x

[7] Callahan D, Phillips E, Carabello R, Frontera WR, Fielding RA. Assessment of lower extremity muscle power in functionally-limited elders. Aging Clin Exp Res 2007; 19: 194-199

[8] Cuk I, Markovic M, Nedeljkovic A, Ugarkovic D, Kukolj M, Jaric S. Force-velocity relationship of leg extensors obtained from loaded and unloaded vertical jumps. Eur J Appl Physiol 2014; 114: 1703-1714

[9] de Vos N], Singh NA, Ross DA, Stavrinos TM, Orr R, Singh MAF. Optimal load for increasing muscle power during explosive resistance training in older adults. J Gerontol A Biol Sci Med Sci 2005; 60: 638-647

[10] Doros G, Lew R. Design based on intra-class correlation coefficients. Am J Biostatistics 2010; 1: 1-8

[11] Garcia-Ramos A, Feriche B, Perez-Castilla A, Padial P, Jaric S. Assessment of leg muscles mechanical capacities: Which jump, loading, and variable type provide the most reliable outcomes? Eur J Sport Sci 2017; 1-9 doi:10.1080/17461391.2017.1304999

[12] Garciá-Ramos A, Haff GG, Padial P, Feriche B. Optimal load for maximizing upper-body power: Test-retest reproducibility. Isokinet Exerc Sci 2016; 24: 115-124

[13] García-Ramos A, Jaric S, Padial P, Feriche B. Force-velocity relationship of upper body muscles: Traditional versus ballistic bench press. J Appl Biomech 2016; 32: 178-185

[14] Garnacho-Castano MV, Lopez-Lastra S, Mate-Munoz JL. Reliability and validity assessment of a linear position transducer. J Sports Sci Med 2015; 14: 128-136

[15] Giroux C, Rabita G, Chollet D, Guilhem G. What is the best method for assessing lower limb force-velocity relationship? Int J Sports Med 2015; 36: 143-149

[16] González-Badillo J], Sánchez-Medina L. Movement velocity as a measure of loading intensity in resistance training. Int J Sports Med 2010; 31: 347-352

[17] Guralnik JM, Simonsick EM, Ferrucci L, Glynn RJ, Berkman LF, Blazer DG, Scherr PA, Wallace RB. A short physical performance battery assessing lower extremity function: association with self-reported disability and prediction of mortality and nursing home admission. J Gerontol A Biol Sci Med Sci 1994; 49: M85-M94

[18] Harriss DJ, Atkinson G. Ethical standards in sport and exercise science research: 2016 update. Int J Sports Med 2015; 36: 1121-1124

[19] Hartmann A, Knols R, Murer K, de Bruin ED. Reproducibility of an isokinetic strength-testing protocol of the knee and ankle in older adults. Gerontology 2009; 55: 259-268

[20] Hopkins WG. Measures of reliability in sports medicine and science. Sports Med 2000; 30: 1-15

[21] Izquierdo M, Cadore EL. Muscle power training in the institutionalized frail: a new approach to counteracting functional declines and very late-life disability. Curr Med Res Opin 2014; 30: 1385-1390 
[22] Izquierdo M, Ibanez ], Gorostiaga E, Garrues M, Zuniga A, Anton A, Larrion JL, Hakkinen K. Maximal strength and power characteristics in isometric and dynamic actions of the upper and lower extremities in middle-aged and older men. Acta Physiol Scand 1999; 167: 57-68

[23] Jaric S. Force-velocity Relationship of muscles performing multijoint maximum performance tasks. Int J Sports Med 2015; 36: 699-704

[24] Jennings CL, Viljoen W, Durandt J, Lambert MI. The reliability of the FitroDyne as a measure of muscle power. J Strength Cond Res 2005; 19: $859-863$

[25] Jiménez-Reyes P, Samozino P, Brughelli M, Morin JB. Effectiveness of an individualized training based on force-velocity profiling during jumping. Front Physiol 2017; 7: 1-13

[26] Komi PV, Bosco C. Utilization of stored elastic energy in leg extensor muscles by men and women. Med Sci Sports 1978; 10: 261-265

[27] Lovell DI, Cuneo R, Gass GC. The blood pressure response of older men to maximum and sub-maximum strength testing. J Sci Med Sport 2011; 14: 254-258

[28] Meylan CM, Cronin JB, Oliver JL, Hughes MM, Jidovtseff B, Pinder S. The reliability of isoinertial force-velocity-power profiling and maximal strength assessment in youth. Sports Biomech 2015; 14: 68-80

[29] Pallarés JG, Sánchez-Medina L, Pérez CE, De La Cruz-Sánchez E, Mora-Rodriguez R. Imposing a pause between the eccentric and concentric phases increases the reliability of isoinertial strength assessments. J Sport Sci 2014; 32: 1165-1175

[30] Pareja-Blanco F, Rodríguez-Rosell D, Sánchez-Medina L, Sanchis-Moysi J, Dorado C, Mora-Custodio R, Yáñez-García JM, Morales-Alamo D, Pérez-Suárez I, Calbet JAL, González-Badillo JJ. Effects of velocity loss during resistance training on athletic performance, strength gains and muscle adaptations. Scand J Med Sci Sports 2017; 724-735 doi:10.1111/sms.12678
[31] Perez-Castilla A, Jaric S, Feriche B, Padial P, Garcia-Ramos A. Evaluation of muscle mechanical capacities through the two-load method: optimization of the load selection. J Strength Cond Res 2017, doi:10.1519/jsc.0000000000001969

[32] Phillips WT, Batterham AM, Valenzuela JE, Burkett LN. Reliability of maximal strength testing in older adults. Arch Phys Med Rehabil 2004; 85: 329-334

[33] Rahmani A, Viale F, Dalleau G, Lacour JR. Force/velocity and power/ velocity relationships in squat exercise. Eur J Appl Physiol 2001; 84: 227-232

[34] Sayers SP, Gibson K. A comparison of high-speed power training and traditional slow-speed resistance training in older men and women. J Strength Cond Res 2010; 24: 3369-3380

[35] Shaw CE, McCully KK, Posner JD. Injuries during the one repetition maximum assessment in the elderly. J Cardiopulm Rehabil Prev 1995; 15: $283-287$

[36] Sleivert G, Taingahue M. The relationship between maximal jumpsquat power and sprint acceleration in athletes. Eur J Appl Physiol 2004; 91: 46-52

[37] Strollo SE, Caserotti P, Ward RE, Glynn NW, Goodpaster BH, Strotmeyer ES. A review of the relationship between leg power and selected chronic disease in older adults. J Nutr Health Aging 2015; 19: 240-248

[38] Wilhelm EN, Rech A, Minozzo F, Radaelli R, Botton CE, Pinto RS. Relationship between quadriceps femoris echo intensity, muscle power, and functional capacity of older men. Age 2014; 36: 1113-1122

[39] Zivkovic MZ, Djuric S, Cuk I, Suzovic D, Jaric S. A simple method for assessment of muscle force, velocity, and power producing capacities from functional movement tasks. J Sport Sci 2016, doi:10.1080/0264 0414.2016 .1221521 